\title{
Risk factors of breast cancer in pre-menopausal women with social perspective
}

\author{
Muzahim K. Al-Khyaat* Dhafer B. Al-Youzbaki** Nuha H. Al-Assaf** \\ *Department of Surgery, ${ }^{*}$ Community Medicine, College of Medicine, University of Mosul.
}

(Ann. Coll. Med. Mosul 2008; 34(2): 100-108).

Received: $2^{\text {nd }}$ Mar 2008; Accepted: $13^{\text {th }}$ Aug 2008.

\begin{abstract}
Objective: To investigate general and socio-economic conditions in the development of breast cancer in pre-menopausal women.

Methods: Between $1^{\text {st }}$ March 2007 to $1^{\text {st }}$. October 2007, we conducted a case-control study, on 52 pre-menopausal women proved to have breast cancer and 80 pre-menopausal women proved to be without breast cancer were considered as controls. The questionnaire included, assessment of socioeconomic factors, life events (stress, social discontinuities and geographical mobility), social context (economic factors, social disintegration, urbanization) and social class. In addition, previous history of surgical operation, parity, history of contraceptive pills usage, and chronic non-communicable diseases and previous X-Rays exposure, were also obtained. Moreover, body mass index and waist to hip ratio were obtained.
\end{abstract}

Results: Regarding Personal Characteristics; positive family history, sedentary life styles, unhealthy dietary behavior, personality type $\mathrm{A}$, and active smoking, all were found to be significantly associated with the occurrence of breast cancer. According to Life Events; stress, social discontinuities and geographical mobility, were also found to be related to the development of breast cancer. Regarding Social Context, both economic factor and social disintegration were found to be highly and significantly associated with breast cancer. According to Other Variables, the presence of one or more of chronic non-communicable diseases in addition to previous exposure to diagnostic X-Rays radiation, having a BMI $>25$, having a WHR $>1$, being in lower social classes and the previous use of oral contraceptive pills were all found to be among the significant risk factors in the development of breast cancer among pre-menopausal women.

Conclusion: Pre-menopausal women with positive family history, sedentary life, unhealthy dietary behavior, personality type A, social discontinuities, active smoking, stress, social discontinuities, geographical mobility, social disintegration, sudden change of economic status, chronic diseases, previous X-Rays exposure, obesity, previous history of oral contraceptive pills usage and being from lower social classes are at high risk of developing of breast cancer. This, indicates the very high responsibility of modern doctors to bear social factors on mind in evaluating such diseases and also in health education.

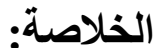

الهـف: التحري عن العو امل الاجتماعية و الاقتصادية و غير ها ودور ها في حدوث سرطان الثذي قبل سن اليأس.

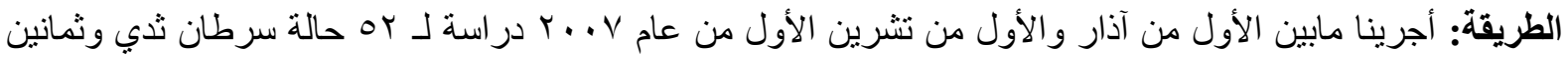

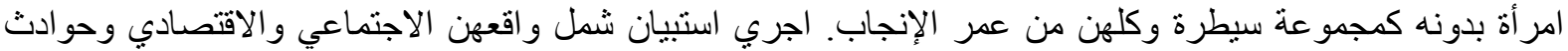

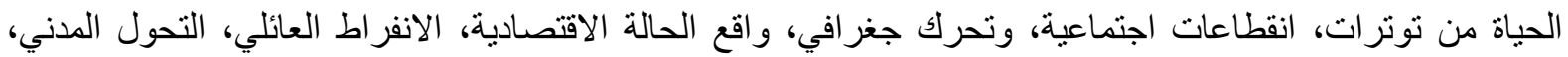

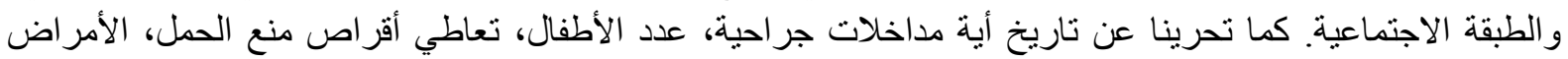




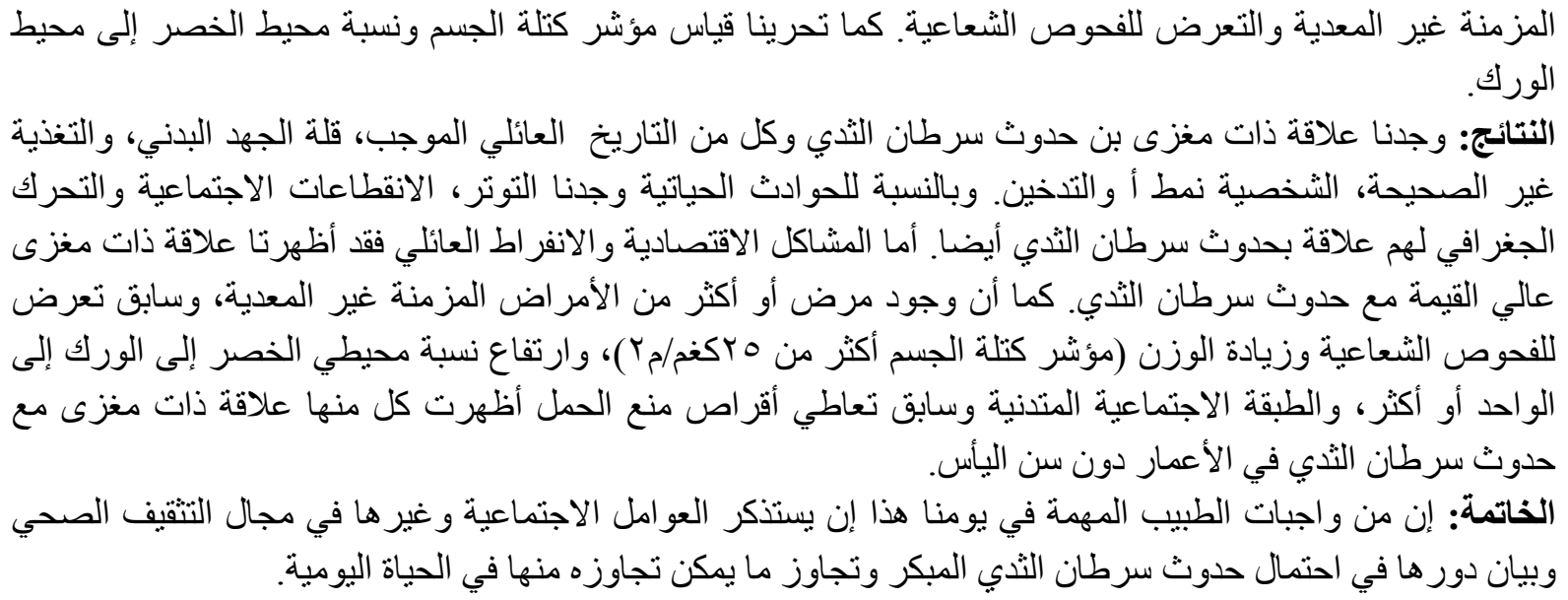

B reast cancer is the most common cancer and the second most common cause of death from cancer in women ${ }^{(1)}$. Because of the high frequency of the disease, breast cancer has always been a source of severe distress to patients and their families. For the same reason, breast cancer research has increased dramatically during the last 2 decades, resulting in extraordinary progress in understanding the disease and in new, more efficient and less toxic treatments. Furthermore, the diffusion of knowledge, the medical advancements, and the increased public awareness have led to earlier diagnosis at stages usually amenable to complete resection and potential cure of the disease ${ }^{(1)}$.

The American Cancer Society estimated that 211240 new cases of breast cancer (32.1\% of all cancers in women) were diagnosed in 2005 in the United States, making breast cancer the most-diagnosed cancer in women. Male breast cancer is a rare disease and 1690 cases were diagnosed for 2005 in the US. Based on cancer cases diagnosed from 1995-1997, the probability of developing invasive cancer is $0.44 \%$ (1 in 225) for women younger than 39 years, $4.15 \%$ ( 1 in 24 ) for women aged $40-59$ years, and $7.02 \%$ (1 in 14) for women aged 60 79 years. The estimated lifetime probability of developing breast cancer is $12.83 \%(\sim 1$ in 8$)$. The likelihood of developing breast cancer is higher in white women than in women of any other racial or ethnic group. Among women aged 20-59 years, breast cancer is the leading cause of death from cancer. However, lung cancer remains the leading cause of death from cancer in women aged 60 years or older ${ }^{(2)}$.

(c) 2008 Mosul College of Medicine
Breast cancer is a heterogeneous disease with no single characteristic cause. Epidemiological studies ${ }^{(3-5)}$ have identified many risk factors that increase the chance for a woman to develop breast cancer, and these include:

1. Factors with relative risk greater than 4 include: Advanced age, being born in North America, northern Europe or Asia, high pre-menopausal blood insulin-like growth factor (IGF), high postmenopausal blood estrogen level, and history of mother and a sister with breast cancer.

2. Factors associated with a relative risk of 2-4 include: High socioeconomic status, age at first full-term pregnancy older than 30 years, history of cancer in one breast, any first-degree relative with a history of breast cancer, history of a benign proliferative lesion, dysplastic mammographic changes, and a high dose of ionizing radiation to the chest.

3. Factors associated with a relative risk of 1.1-1.9 include: Nulliparity, early menarche (age $<11$ year), late menopause (age >55 year), postmenopausal obesity, high-fat diet/saturated fat-rich diet, residence in urban areas, white race-Older than 45 years, black race- Younger than 45 years and history of endometrial or ovarian cancer.

Early breast cancer can in some cases present as breast pain (mastodynia) or a painful lump ${ }^{(5)}$. A lump under the arm or above the collarbone that does not go away may be present. When breast cancer has invaded the dermal lymphatics - small lymph vessels of the skin, its presentation can resemble skin inflammation and thus is known as inflammatory breast cancer. In inflammatory 
breast cancer, the breast cancer is blocking lymphatic vessels and this can cause pain, swelling, warmth, and redness throughout the breast, as well as an orange peel texture to the skin referred to as peau d'orange. Changes in the appearance or shape of the breast can raise suspicions of breast cancer. Another reported symptom complex of breast cancer is Paget's disease of the breast ${ }^{(6)}$. The appearance of a new breast symptom should be taken seriously by both patients and their doctors, because of the possibility of an underlying breast cancer at almost any age. Occasionally, breast cancer presents as metastatic disease, that is, cancer that has spread beyond the original organ. Metastatic breast cancer will cause symptoms that depend on the location of metastasis. More common sites of metastasis include bone, liver, lung, and brain. Unexplained weight loss can occasionally herald an occult breast cancer, as can symptoms of fever or chills. Bone or joint pains can sometimes be manifestations of metastatic breast cancer, as can jaundice or neurological symptoms. Pleural effusions are not uncommon with metastatic breast cancer. Obviously, these symptoms are "non-specific," meaning they can also be manifestations of many other illnesses ${ }^{(7,8,9)}$.

\section{Patients and methods:}

In order to achieve the aim of the present study, a case-control study design was adopted, 52 pre-menopausal women (all cases were reached by the breast cancer center in Mosul governorate) were enrolled in this study as cases according to the following inclusion criteria: the participant, must be a pre-menopausal woman; proved to have breast cancer by documented histopathological examination for her breast mass.

Another 80 women (all controls were reached by the breast cancer center in Mosul governorate) were chosen as control for this study with the following inclusion criteria: the participant, must be a pre-menopausal woman and proved to not have breast cancer by documented histo-pathological examination for her breast mass.
Un-paired sampling technique was used in this study, matching was done for age $( \pm 5$ years). Every woman in this study was interviewed by the researchers and the following questions to participants were answered in addition to the specific prior anthropometric measurements. The presence of one or more of the chronic noncommunicable diseases, previous history of any surgical operation and social class was obtained according to occupational social classification10 were all included in the questionnaire form. Socio-economic factors were obtained according to the following:

Social factors in health and disease ${ }^{(10)}$ :

1. Personal characteristics:

A. Social identity:

Not modifiable: Age, sex and heredity (family history of breast cancer in primary relatives)

Modifiable: Such as marital status, and occupation.

B. Personal habits:

Sedentary life style.

Smoking.

Alcohol consumption.

Fatty, calorie and salt rich diets (unhealthy diets)

C. Psychological make-up:

Personality type $A$

Personality type B

II - Life Events:

Stress

Social Discontinuities:

Death of spouse

Change in marital status (such as divorce, recent marriage, single or widowed)

Retirement and change in the job

Change of residence

The birth of new baby

Geographical mobility:

- Rural to urban, Urban to rural of any type.

Catastrophic events.

III - Social Context:

A. Economic factors:

- Unemployment.

- Very high employment

- Sudden job descent.

- Sudden loss of huge money.

\section{B. Social disintegration}


- Living alone, or with family

\section{Urbanization:}

- Urban or rural

- Crowding index

Then the Odds ratio was calculated for every risk factor of concern in this study with its $p$ value. Special statistical analysis (by Excel from Windows XP version 2003) was used to examine the effect for results in this study.

\section{Results:}

The mean age of the study population was 31.6 years for cases and 31.9 years for controls. The results of examining social risk factors in the development of breast cancer appeared as the following:

Table (1) shows the distribution of cases and controls according to personal characteristics and reveals regarding social identity that positive family history is found to be significantly associated with the development of breast cancer $(\mathrm{OR}=13.22, \mathrm{P}$-value $=0.000$, and $95 \%$ C.I.=5.92-29.52), the same thing is applied to sedentary lifestyle $(O R=51$, $P$ value $=0.000$, and 95\% C.I.=13.61-191.16). Furthermore, unhealthy dietary behavior is again found to be highly associated with the occurrence of breast cancer (OR=27.36, $\mathrm{P}$ value $=0.0000$, and 95\% C.I.=8.99-84.91). Personality type $A$, is also found to be associated with incident of breast cancer (OR=58.33, P-value=0.000, and 95\% C.I.=20.11-169.22). Active smoking is found to be significantly associated with the occurrence of breast cancer $(\mathrm{OR}=3.46, \mathrm{P}$-value $=0.043$, and 95\% C.I.=1.04-11.48).

Table (2) indicates that stress is highly and significantly associated with breast cancer
(OR=69.00, P-value $=0.000, \quad$ and $95 \%$ C.I.=22.98-200.16). Moreover, social discontinuities and geographical mobility, both of them are also found to be related to the development of breast cancer $(\mathrm{OR}=29.4$, $\mathrm{P}$ value $=0.000$, and $95 \%$ C.I. $=12.63-68.43)$, (OR=9.46, P-value=0.000, and 95\% C. $\mathrm{I} .=3.04-29.4)$ respectively.

Table (3) reveals that economic factor (OR= 52.6, P-value $=0.000$, and $95 \%$ C.I. $=21.11$ 180.13) and social disintegration $(\mathrm{OR}=67.1, \mathrm{P}$ value $=0.000$, and $95 \%$ C.I. $=21.56-167.12$ ) both are highly and significantly associated with breast cancer.

Table (4) indicates that the presence of one or more of chronic non-communicable diseases is associated with the occurrence of breast cancer $(O R=3.50, P$-value $=0.001$, and 95\% C.I.=1.69-7.26). Previous exposure to XRays radiation is also found to be associated with breast cancer $(\mathrm{OR}=3.43, \mathrm{P}$-value $=0.001$, and 95\% C.I.=1.61-7.31). Both, BMI > 25 and WHR $>1$ are found to be associated with the occurrence of breast cancer $(\mathrm{OR}=18$, $\mathrm{P}$ value $=0.000$, and $95 \%$ C.I.=7.01-46.20), $(\mathrm{OR}=14.81, \mathrm{P}$-value $=0.001, \quad$ and $\quad 95 \%$ C.I.=2.97-73.75) in that order. Women in lower social classes are found to be at risk of developing breast cancer $(\mathrm{OR}=10.90$, $\mathrm{P}$ value $=0.000$, and $95 \%$ C.I.=4.94-24.04). Finally, the use of oral contraceptive pills is found to be among the significant risk factors in the development of breast cancer among pre-menopausal women.

Table(1): Distribution of the study population according to personal characteristics

\begin{tabular}{|c|c|c|c|c|c|c|c||}
\hline \multirow{2}{*}{ Factor } & \multicolumn{2}{|c|}{ Cases $(\mathrm{n}=\mathbf{5 2})$} & \multicolumn{2}{c|}{ Controls $(\mathrm{n}=\mathbf{8 0})$} & \multirow{2}{*}{ O R } & P-value & 95 \% C.I. \\
\cline { 2 - 8 } & No. & $\%$ & No. & $\%$ & & & \\
\hline $\begin{array}{c}\text { Positive family } \\
\text { history }\end{array}$ & 43 & 65.4 & 10 & 12.5 & 13.22 & 0.000 & $5.92-29.52$ \\
\hline Sedentary life & 51 & 98.1 & 40 & 50.00 & 51 & 0.000 & $13.61-191.16$ \\
\hline $\begin{array}{c}\text { Active } \\
\text { smoking }\end{array}$ & 8 & 15.4 & 4 & 5.00 & 3.46 & 0.043 & $1.04-11.48$ \\
\hline $\begin{array}{c}\text { Unhealthy dietary } \\
\text { behavior }\end{array}$ & 50 & 96.2 & 38 & 47.5 & 27.36 & 0.0000 & $8.99-84.91$ \\
\hline $\begin{array}{c}\text { Personality type } \\
\text { A }\end{array}$ & 59 & 96.2 & 24 & 30.00 & 58.33 & 0.000 & $20.11-169.22$ \\
\hline
\end{tabular}


Table (2): Distribution of the study population according to life events.

\begin{tabular}{|l|l|l|l|l|l|l|l||}
\hline \multirow{2}{*}{ Factor } & \multicolumn{2}{|l|}{ Cases $(\mathrm{n}=\mathbf{5 2})$} & \multicolumn{2}{l|}{ Controls $(\mathrm{n}=\mathbf{8 0})$} & \multirow{2}{*}{ P-value } & 95 \% C.I. \\
\cline { 2 - 9 } & No. & $\%$ & No. & $\%$ & & & \\
\hline Stress & 51 & 98.1 & 4 & 5.00 & 69.00 & 0.000 & $22.98-200.16$ \\
\hline $\begin{array}{l}\text { Social } \\
\text { discontinuities }\end{array}$ & 42 & 80.8 & 10 & 12.5 & 29.4 & 0.000 & $12.63-68.43$ \\
\hline $\begin{array}{l}\text { Geographical } \\
\text { mobility }\end{array}$ & 14 & 6.4 & 3 & 3.8 & 9.46 & 0.000 & $3.04-29.4$ \\
\hline \hline
\end{tabular}

Table (3): Distribution of the study population according to social context

\begin{tabular}{|c|c|c|c|c|c|c|c||}
\hline \multirow{2}{*}{ Factor } & \multicolumn{2}{|c|}{ Cases (n=52) } & \multicolumn{2}{c||}{ Controls (n=80) } & \multirow{2}{*}{ O R } & \multirow{2}{*}{ P-value } & \multirow{2}{*}{95 \% C.I. } \\
\cline { 2 - 7 } & No. & $\%$ & No. & $\%$ & & & \\
\hline \hline Economic factor & 50 & 96.2 & 8 & 10.0 & 52.6 & 0.000 & $21.11-180.13$ \\
\hline $\begin{array}{c}\text { Social } \\
\text { disintegration }\end{array}$ & 38 & 73.1 & 2 & 2.5 & 67.1 & 0.000 & $21.56-167.12$ \\
\hline Urbanization & 46 & 88.5 & 68 & 85.00 & 1.35 & 0.571 & $0.48-3.81$ \\
\hline
\end{tabular}

Table (4): Distribution of the study population according to other variables

\begin{tabular}{|c|c|c|c|c|c|c|c||}
\hline \multirow{2}{*}{ Variables } & \multicolumn{2}{|c|}{ Cases (n=52) } & \multicolumn{2}{c|}{ Controls (n=80) } & \multirow{2}{*}{ O R } & P-value & \multirow{2}{*}{ 95 \% C.I. } \\
\cline { 2 - 7 } & No. & $\%$ & No. & $\%$ & & & \\
\hline Chronic diseases & 28 & 53.8 & 20 & 25 & 3.50 & 0.001 & $1.69-7.26$ \\
\hline Previous X-Ray & 24 & 46.2 & 16 & 20 & 3.43 & 0.001 & $1.61-7.31$ \\
\hline Previous surgery & 18 & 34.6 & 16 & 20 & 2.12 & 0.061 & $0.97-4.65$ \\
\hline BMI > 25 kg/m2 & 48 & 92.3 & 32 & 40 & 18 & 0.000 & $7.01-46.20$ \\
\hline WHR >1 & 51 & 98.1 & 62 & 77.5 & 14.81 & 0.001 & $2.97-73.75$ \\
\hline Lower social classes & 33 & 63.5 & 11 & 13.8 & 10.90 & 0.000 & $4.94-24.04$ \\
\hline Oral contraceptives & 38 & 73.1 & 9 & 11.3 & 21.41 & 0.000 & $9.35-49.02$ \\
\hline
\end{tabular}

\section{Discussion:}

Lifestyle changes can modify the risk of developing breast cancer, and this phenomenon is supported by several lines of evidence. First, rates of breast cancer incidence vary widely by geographic areas around the world. Only a small part of these differences is due to genetics, few chemical or other carcinogen exposures have been linked to risk, and the remainder of cases are, therefore, due to individual health and lifestyle behaviors $^{(11)}$. Second, within-country changes over time in breast cancer incidence have been paralleled by great lifestyle and health behavior changes ${ }^{(12)}$. Third, experimental 
animal and human models provide confirmation of observable effects of several lifestyle behaviors on breast biology ${ }^{(12)}$.

Certain predisposing factors in the development of breast cancer are clear. For instance, women at high risk include those who have a family history of breast cancer, particularly first-degree relatives (mother, sister, and maternal aunt) ${ }^{(13,14)}$. The present study showed highly significant association of breast cancer with positive family history.

There is a quickly growing body of epidemiologic data on the association between exercise and breast cancer, which was reviewed in depth by Thune and Furberg $^{(15)}$. Over 20 published cohort studies have investigated the association between physical activity and risk of breast cancer, the majority of which showed clear evidence of a lower risk for breast cancer in women who were classified at the highest levels of physical activity. The reduction in risk ranged from $10 \%-70 \%$ for the most active women and, on average, was 30\%-40\% lower for women who exercised for 3-4 hours per week at moderate to vigorous levels. The definition of "most active" varied greatly by study and depended on the questions asked, the population studied, and the researchers' choice of categories for amounts of activity. The findings from the present work go in consistence with the above conclusion, where sedentary lifestyle was found to be an important operational risk factor in the development of breast cancer in premenopausal women.

Unhealthy dietary behavior (Western type of diets), which includes heavy intake of salt, fat and refined sugars, was found, in this study, to be highly and significantly associated with the occurrence of breast cancer. Several investigators examined particular international and intercultural dietary differences and proposed that diets that are low in fat and high in fruits, vegetables, fiber, and complex carbohydrates (i.e. healthy diets) might lower risk for breast cancer ${ }^{(16,17)}$. Moreover, animal experimental studies have shown a higher rate of development (via promotion of tumorigenesis) of mammary tumors with greater polyunsaturated or saturated fats intake ${ }^{(39)}$. However, it is not clear if the dietary fat per se, or the greater energy intake, was responsible for the greater development of mammary tumors in those studies ${ }^{(18)}$.

Findings from the Western Collaborative Group study and the Framingham heart study seemed to establish type A behavior (the triad of competitive ambition, time urgency, and hostility) as a risk factor for cardiovascular disease ${ }^{(19)}$. Til et $\mathrm{al}^{(20)}$, found in their large population cohort study in UK, a significant association between personality type $A$ and the occurrence of myocardial infarction and breast cancer. In the present study, a very significant association $(P=0.000)$ also was found between personality type $A$ and the development of breast cancer.

Active smoking in this study was found to be an important operational risk factor in the causation of breast cancer in pre-menopausal women. No matter of discussion nowadays, that active smoking is being one of the most carcinogens to organs and tissues in the human body ${ }^{(21-23)}$.

Breast cancer is the most common cancer in women in terms of both incidence and prevalence. It is a hormone dependent disease with a clear positive relation to high endogenous concentrations of estrogen ${ }^{(24)}$. The role of stress in the etiology of breast cancer has been an area of emerging interest, partly because of the ability of stress to affect the hormonal system and especially estrogen synthesis $^{25}$. A potential relation between stress and risk of breast cancer has been examined in studies with different designs and with conflicting results ${ }^{(26,27)}$. In the present study, stress emerged as a highly significant factor $(P=0.000)$ in the causation of breast cancer with a very high OR (69), this actually may be an overestimation of the true situation because breast cancer is a major health event and the problem of recalling bias can not be excluded totally from such type of a study (case-control study). Social discontinuities and geographical mobility, both appeared in this study to be associated significantly with the development of breast cancer in premenopausal women. This may be partly 
shared with stress mechanism, since these two events are among the most stressful life events including loss of self-congruence, loss of social cohesion and major changes in macro and micro social context of the human. Moreover, sudden change in economic status and social disintegration, both showed significant association with breast cancer in this work.

Urbanization had been linked with the development of different types of cancers and breast cancer is one of most important of them. This association, seems mostly due to lack of urban people to solar ultraviolet-B radiation than their counter part rural residence and many other factors ${ }^{(25)}$. Grant ${ }^{(28)}$ found that urbanization is associated with breast cancer in most states of the USA in 2002. However, in this study, urbanization, appeared not to be associated with the occurrence of breast cancer, this mostly seems because the sample of this study is not representative to the whole community of breast cancer. And this is one drawback of the case-control study. Cohort studies may be more reasonable in examining such factor. The presence of one or more of chronic non-communicable diseases appeared from this study to be significantly $(P=0.001)$ associated with the development of breast cancer in pre-menopausal women. The earliest reports of the positive association between energy balance and breast cancer date back to $1942^{(29)}$. Numerous case-control and cohort studies have subsequently supported this association. The WHR, a measure of central adiposity, is gaining increased use as a measure of etiologically significant obesity and is thought to be more closely related to pathology, especially coronary heart disease, diabetes mellitus and stroke ${ }^{(30)}$. The metabolic changes that accompany obesity include peripheral hyperinsulinemia, hyperglycemia and glucose intolerance, increased serum very low-density lipoprotein, increased serum leptin, dyslipidemia, increased serum cortisol clearance, increased serum C-peptide level, down-regulation of insulin receptors and an exaggerated insulin response to an oral glucose load. These changes, especially when they occur in early adulthood, may be of fundamental importance in the development of breast cancer ${ }^{(31)}$. In this study, central obesity also appeared to be significantly associated $(\mathrm{P}=0.001)$ with the occurrence of breast cancer. However, general obesity, as measured by BMI showed more significant association $(P=0.000)$ with breast cancer.

Exposure to ionizing radiation has been shown to be associated with a significant increase in breast cancer risk. Epidemiologic studies of atomic bomb survivors, such as the Life Span Study, and of medically irradiated populations show increased risks of female breast cancer, with relative risks ranging from 1.0 to 4.3 per Gy. Most of the information about patterns of risk over time comes from studies of populations who received relatively moderate to high doses of radiation to the breast. The increased risk of breast cancer starts to be observed 10 to 15 years after exposure, with relative risks decreasing as a function of attained age after reaching a peak, usually between age 30 and 40 years ${ }^{(32,33)}$. In the present study, pre-menopausal women who have been exposed to previous diagnostic X-rays, appeared to be at high risk in the development of breast cancer (OR=3.43, $\mathrm{P}=0.001,95 \% \mathrm{C} . \mathrm{I} .=1.61-7.31)$.

In studies of breast cancer incidence and mortality, socioeconomic status has been measured by length of education, area of residence, occupation and education, and occupational groups. Both the highest incidence and the highest mortality have almost uniformly been found in women with a long and higher education ${ }^{(34,35)}$. In present study, different results were obtained regarding the effect of social class in the development of breast cancer, where premenopausal women in the lower social classes are found to be at higher and significant risk of developing the disease. Actually, this can be explained according to the cultural and social differences between Western and Eastern societies.

In a pooled analysis of 54 studies, the relative risk of breast cancer among women who were currently using oral contraceptives, as compared with those who had never used 
them, was 1.24 (95 percent confidence interval, 1.15 to 1.33$)^{(36)}$. In the current study, significant association was found between the use of oral contraceptives and the development of breast cancer. Nevertheless, in another recent study among women from 35 to 64 years of age, no significant association between oral contraceptives use and breast cancer was found.

\section{References:}

1. Jemal A, Murray T, Ward E: Cancer statistics. CA Cancer J Clin, 2005; 55 (1): 10-30.

2. Goldhirsch A, Glick JH, Gelber RD. Meeting highlights: International Consensus Panel on the Treatment of Primary Breast Cancer. Seventh International Conference on Adjuvant Therapy of Primary Breast Cancer. J Clin Oncol, 2001; 15: 3817-3827.

3. Montgomery LL, Tran KN, Heelan MC. Issues of regret in women with contralateral prophylactic mastectomies. Ann Surg Oncol, 1999; 6 (6): 546-52, 1999.

4. Collaborative Group on Hormonal Factors in Breast Cancer: Breast cancer and breastfeeding: collaborative reanalysis of individual data from 47 epidemiological studies in 30 countries, including 50302 women with breast cancer and 96973 women without the disease. Lancet, 2002; 360 (9328): 187-195.

5. Smith IE, Dowsett M. Aromatase inhibitors in breast cancer. N Engl J Med, 2003; 348 (24): 2431-2442.

6. Espey DK, Wu XC, Swan J. "Annual report to the nation on the status of cancer, 19752004, featuring cancer in American Indians and Alaska Natives". Cancer, 2007; 110 (10): 2119-52.

7. Fletcher SW, Black W, Harris R, Rimer BK, Shapiro S. "Report of the International Workshop on Screening for Breast Cancer". J. Natl. Cancer Inst., 2007; 85 (20): 1644-1656.

8. Rusiecki JA, Holford TR, Zahm SH, Zheng $\mathrm{T}$. Breast cancer risk factors according to joint estrogen receptor and progesterone receptor status. Cancer Detect Prev, 2005; 29: 419-426.
9. Robb C, Haley WE, Balducci L, Extreman M, Perkins EA, Small BJ, Mortimer J. Impact of breast cancer survivorship on quality of life in older women. Critical Reviews in Oncology and Hematology, 2007; 62(1): 84-91.

10.Al-Youzbaki DB. Scientific Social Etiology of the Diseases. In: Cultural Sociology for Health and IIIness. 2007. Dar Ibn Al-Atheer for Printing and Publishing. University of Mosul. IRAQ.Pp 222-228.

11.IARC Working Group on the Evaluation of Cancer-Preventive Agents. Weight Control and Physical Activity, IARC Handbooks of Cancer Prevention, Volume 6. Lyon, France: IARC, 2002.

12. McTiernan A. Associations between energy balance and body mass index and risk of breast carcinoma in women from diverse racial and ethnic backgrounds in the U.S. Cancer, 2000; 88(5):1248-1255.

13.Cannuscio CC, Jones C, Kawachi I. Reverberations of family illness: a longitudinal assessment of informal caregiving and mental health status in the Nurses' Health Study. Am J Public Health, 2002; 92: 1305-11.

14.Fisher L, Lieberman MA. Alzheimer's disease: the impact of the family on spouses, offspring, and inlaws. Fam Process, 1994; 33: 305-25.

15. Thune I, Furberg AS. Physical activity and cancer risk: dose-response and cancer, all sites and site-specific. Med Sci Sports Exerc, 2001; 33 (6):S530-S550.

16. Marshall JR, Qu Y, Chen J. Additional ecological evidence: lipids and breast cancer mortality among women aged 55 and over in China. Eur J Cancer, 1992; 28A: 1720-1727.

17. Prentice RL, Kakar F, Hursting $S$ et al. Aspects of the rationale for the Women's Health Trial. J Natl Cancer Inst, 1988; 80: 802-814.

18. World Cancer Research Fund Panel (Potter JD Chair). Food, Nutrition and the Prevention of Cancer: a Global Perspective. Washington, DC: American Institute for Cancer Research, 1997. 
19. Ragland DR, Brand RJ. Type A behaviour and mortality from coronary heart disease. N Engl J Med, 1988; 318: 65-69.

20.Til S, Petra H, Manfred A. Personality, lifestyle, and risk of cardiovascular disease and cancer: follow-up of population based cohort. BMJ 2006; 332: 1359-1362.

21.Dorgan JF, Baer DJ, Albert PS, Judd JT, Brown ED, Corle DK, et al. Serum hormones and the alcohol-breast cancer association in postmenopausal women. J Natl Cancer Inst 2001;93(9):710-5.

22. Kristan A. Alcohol: a recently identified risk factor for breast cancer. CMAJ, 2003; 168 (9): 122-125.

23. World Health Organization. Global status report on alcohol. Geneva: The Organization; 1999. Cat no WHO/HSC/SAB/99.11.

24. Hankinson S, Hunter D. Breast cancer. In: Adami $\mathrm{H}$, Hunder $\mathrm{D}$, Trichopoulos $\mathrm{D}$, eds. Textbook of cancer epidemiology. New York: Oxford University Press, 2002: 301339.

25. Helgesson O, Cabrera C, Lapidus L, Bengtsson C, Lissner L. Self-reported stress levels predict subsequent breast cancer in a cohort of Swedish women. Eur J Cancer Prev, 2003; 12: 377-381.

26. Kroenke $\mathrm{CH}, \quad$ Hankinson SE, Schernhammer ES, Colditz GA, Kawachi I, Holmes MD. Caregiving stress, endogenous sex steroid hormone levels, and breast cancer incidence. Am J Epidemiol, 2004; 159: 1019-27.

27.Grant WB. An ecologic study of dietary and solar ultraviolet-B links to breast carcinoma mortality rates. Cancer. 2002; 94: 272-281.

28. Tannenbaum A. Genesis and growth of tumors. Effects of caloric restriction per se. Cancer Res. 1942; 2: 460-467.
29.Lev-Ran A. Human obesity: an evolutionary approach to understanding our bulging waistline. Diabetes Metab Res Rev, 2001; 17: 347-362.

30. Stoll BA. Upper abdominal obesity, insulin resistance and breast cancer risk. Int $\mathrm{J}$ Obes Relat Metab Disord, 2002; 26: 747753.

31.Preston DL, Mattsson A, Holmberg E, et al: Radiation effects on breast cancer risks: A pooled analysis of eight cohorts. Radiat Res, 2002;158: 220-235

32. Ronckers CM, Erdmann CA, Land CE. Radiation and breast cancer: $A$ review of current evidence. Breast Cancer Res, 2005; 7: 21-32,

33.Lund E, Jacobsen BK. Education and breast cancer mortality: experience from a large Norwegian cohort study. Cancer Causes Control, 1991; 2: 235-238.

34. Martikainen $\mathrm{P}$, Valkonen $\mathrm{T}$. Diminishing educational differences in breast cancer mortality among Finnish women: a registerbased 25-year follow-up. Am J Public Health, 2000; 90: 277-280.

35. Collaborative Group on Hormonal Factors in Breast Cancer. Breast cancer and hormonal contraceptives: collaborative reanalysis of individual data on 53297 women with breast cancer and 100239 women without breast cancer from 54 epidemiological studies. Lancet, 1996; 347: 1713-1727.

36.Polly AM, Jill AM, Hoyt G. Oral Contraceptives and the Risk of Breast Cancer. New Eng J Med, 2002; 346: 20252032. 